\title{
Bridging the Gap between Energy Management Systems and Machine Tools - Embedded Energy Efficiency in Production Planning and Control
}

\author{
Manuel Rippel*, Olga Willner, Johannes Plehn, and Paul Schönsleben \\ ETH Zurich, BWI Center for Industrial Management, Zurich, Switzerland \\ mrippel@ethz.ch
}

\begin{abstract}
Global environmental challenges lead to a rising importance of resource efficiency in industry. The strong environmental impact of manufacturing processes necessitates a significant reduction of the amount of employed resources. Therefore, the potential of production planning and control (PPC) systems is analyzed from a top-down and bottom-up perspective in terms of increasing the energy efficiency of manufacturing processes. A conceptual approach is developed to embed energy efficiency in a PPC-logic in order to link managerial targets with machine tools located on the shop-floor.
\end{abstract}

Keywords: PPC, Process Chain, Energy Efficiency, Energy profile.

\section{Motivation and Purpose}

Scarcity of resources and rising energy prices caused by an increasing primary energy demand started to change society and business values. Today, companies have to tackle three essential challenges related to global environmental issues: (1) legislation and governmental regulations, (2) consumer and public awareness, (3) resource and energy prices and $\mathrm{CO}_{2}$-costs [1]. These challenges lead to an increasing importance of resource efficiency and in particular energy efficiency in European manufacturing industry. Manufacturing is directly connected to natural resources, since this sector is responsible for about $33 \%$ of the primary energy use and for $38 \%$ of the $\mathrm{CO}_{2}$ emissions [2].

The efficient use of energy in manufacturing is seen as an effective approach to decrease the energy needs and the associated $\mathrm{CO}_{2}$ emissions [1]. Moreover, it is, and will be even more in future, a central competitive factor, since resource efficiency is gaining importance next to economic objectives. The challenge for manufacturing companies is to tackle the assumed dichotomy between competitive and environmental friendly operations.

The significance of this field can be illustrated by looking at the German industry, which accounts for around 46\% of the country's overall energy consumption [3]. Experts estimate that $10-15 \%$ of this amount is consumed by machine tools for

\footnotetext{
* Corresponding author.

C. Emmanouilidis, M. Taisch, D. Kiritsis (Eds.): APMS 2012, Part I, IFIP AICT 397, pp. 80-87, 2013.

(C) IFIP International Federation for Information Processing 2013
} 
machining operations [3]. Since $99 \%$ of the environmental impacts of machine tools are due to the consumption of electrical energy, the energy consumption is solely considered in this paper [4].

The Smart Manufacturing Consultation Group of the European Commission for energy efficiency declares that "it is necessary to develop tools and relevant algorithms which will be able to take energy efficiency into account as a significant parameter of the process, and to calculate best energy performance results along with other desired process results" [5]. Hence, the objective is to identify and analyze the potential of production planning and control (PPC) systems, in order to increase the energy efficiency in manufacturing processes.

\section{Methodological Approach}

This paper is mainly based on qualitative research. A literature analysis is conducted with a focus on energy efficiency in the manufacturing industry both from a managerial and a technical background. A "Top-down/Bottom-up" process is used as a hierarchical analysis, in order to assure a structured approach. As depicted in Figure 1 , this paper conceptually and methodologically systematizes existing concepts from Energy Management Systems (EMS) as top-down perspective and from process chain level respectively machine tools as bottom-up perspective. The process for achieving energy efficiency in production systems is categorized in four steps: data collection, data visualization, evaluation and improvement measures. The key elements for embedding energy efficiency in a PPC-logic are reviewed and allocated to four overlaying levels of analysis: data, model, system and logic.

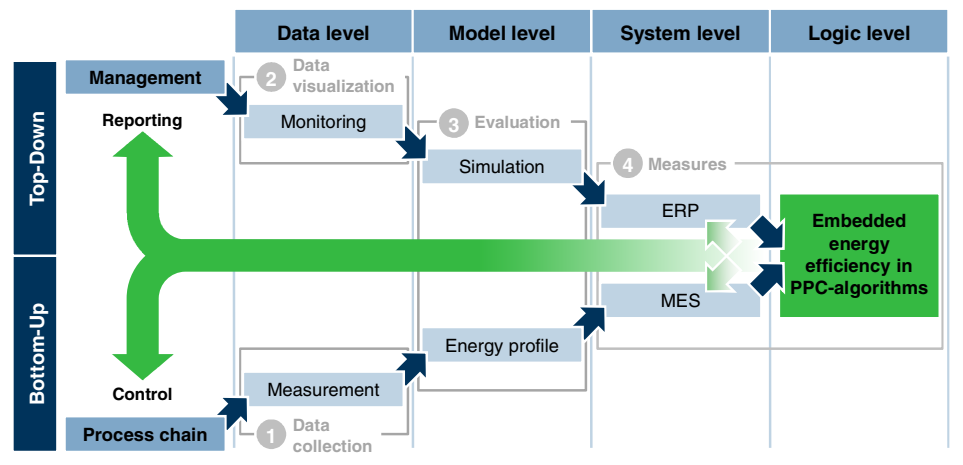

Fig. 1. Top-down and bottom-up analysis process

\section{$3 \quad$ Findings}

This section presents the findings by identifying essential elements for increasing energy efficiency in production systems as a combination of superior management perspective and the technical entities within the process chain. 


\subsection{Bottom-Up Perspective: Process Chain}

Manufacturing companies underestimate their potential to save energy and reduce related costs. For example, studies have shown saving potential of $25-30 \%$ in production [6]. Due to this promising impact, the focus of the bottom-up perspective is mainly on ongoing research to improve the energy efficiency of machine tools as operating elements of process chains.

Most machine tool suppliers and end users lack knowledge about time-dependent energy demand during operation [7]. Significant improvement potential is expected by enhancing transparency of energy consumption of machine tools and its components [6]. The measurement of machine tools with regard to energy used and material consumed is seen as the first step in order to understand, characterize and improve environmental impact and energy consumption of manufacturing processes [3] [8].

Energy demand of machine tools is primarily considered as an estimated value under either nominal or extreme conditions [11]. However, energy consumption is distinctly dynamic due to the temporal power demand throughout a machining process. It significantly depends on the operating states, like e.g. turn-off, start-up, warm-up, stand-by, processing or stopping [9] [10]. Furthermore, power demand while processing depends on several further factors, e.g. process design, selected machine tool, machine dynamics and process parameters [11] [7]. Taking into account these characteristics, it is not sufficient to consider energy consumption on average, but to provide time-dependent energy profiles for further evaluation. It is detected that the energy demand of machine tools consists of the fixed power as base load, which sets the process-time depending share of required energy for the machining of the work piece, and the variable power, which depends on the process [9].

The metering and monitoring of energy consumption of single machinery is time consuming and expensive. Furthermore, it is not feasible to measure energy demands considering all potential influencing factors among all machines in a factory [11]. Therefore, it is intended to define standards for the measurement considering operating state, consumer and exemplary processes and to formalize the results in appropriate models supporting the case-specific quantification [9]. Thereby, it is at least possible to rate and evaluate the scale of the consumption ex-ante or ex-post. Upcoming new sensor technologies within Information \& Communication Technologies (ICT) enable to perform in-process measurement, which will provide more accurate information about temporal energy demands [12]. Thereby, the energy-oriented evaluation can be conducted continuously based on real-time data and decision makers can react instantaneously by taking dynamic measures.

Furthermore, ongoing research activities are analyzing when and under which conditions components can be deactivated or at least reduced in non-productive situations. However, the optimization is limited to single machines. There is no technological approach pursued in machine tool industry to aim at a dynamic energetic optimum for the whole process chain.

\subsection{Top-Down Perspective: Energy Management Systems}

Up to now, solely one third of all companies have a systematic evaluation and optimizing approach for their energy consumption [6]. Mostly, they just have an overall 
recording of data referring to their energy consumption, whereby they are not aware of their specific energy use and loss within production [6]. Several tools and methods are presently developed in this research area.

Monitoring and simulation are seen as essential elements of energy management [1]. Key Performance Indicators (KPIs) are developed to evaluate if changes in the process for increasing energy efficiency have a verifiable benefit [13]. Their monitoring supports assessment of optimization potentials and visualization of benefits from improvement measures. There exist various structural and explanatory indicators, since the variety and complexity of industrial processes set different requirements [1].

The evaluation of energy costs, environmental impacts and technical performance are of major importance in order to achieve a holistic image of the factory [14]. Different analytical techniques can be consulted for evaluating energy efficiency improvements in terms of economic impact, e.g. net present value method (NPV), the method of annualized value, the method of internal rate of return or payback period. However, it is difficult to quantify potential benefits in monetary terms for an economic evaluation [13].

Simulation can support to analyze the dynamic energy consumption behavior, operational data and interdependencies of machine tools and other technical equipment involved. It can be used to provide an overview of the system's performance on a realistic base. Simulation tools enable decision making to assess the expected effects of measures for improving the environmental performance both on process chain or machine level [15] [16].

However, a comprehensive portfolio of measures is still missing. The range of energy efficiency measures is limited to static approaches such as replacement of components, acquisition of new machinery or installation of fixed equipment. Dynamic approaches for reacting on short-term changes of the system's energy state are missing or are not fully developed.

\subsection{Synthetic Link: Embedded Energy Efficiency in PPC}

The above mentioned data and concepts from each perspective have to be utilized and adjusted with regard to a multi-object approach. Bunse et al. proposed to extend the scope of MES, ERP and simulation software to optimize processes throughout the whole production in terms of energy efficiency [1]. In the following, an integral PPCconcept is outlined, since PPC can exploit existing configuration flexibility within economic optimization of production systems for embedding also energy efficiency as optimization criteria.

PPC will not solely be used as information source for the economic values for monitoring of KPIs anymore. Therefore, the defined and monitored KPIs in EMS will be split into operational variables. Prior PPC algorithms solely focused on direct economic and technical aspects. They have to be extended for environmental aspects. By doing so, both energy-related costs and environmental footprint of the products can be enhanced. The extended PPC-logic provides the organizational conditions for exploiting several characteristics and technological developments of machine tools for increasing energy efficiency as follows:

First, the above mentioned characteristic of the energy profiles of time-dependent energy consumption consisting of fixed and variable power can be exploited. It is 
possible to reduce energy consumption per part by enhancing the productivity of the machine tool respectively the capacity utilization [8]. The resulting shorter production time enables savings of fixed power of the machine's base load. This saving is higher than the additional consumption within the process-dependent variable power [17]. PPC-algorithms have to consider within machine scheduling that the material removal rate (MRR) can be maximized in order to reduce the impact of fixed power share. Furthermore, the machine tool consumes a fixed amount of energy during non-value adding tasks (e.g. setting-up, handling) [18]. Those tasks have to be avoided as far as possible or the time required needs to be reduced by energy-oriented process and production planning, since the energy is wasted without adding value on the product.

Second, stand-by strategies for machine tools should be integrated in production scheduling in order to reduce energy consumption within the remaining nonproductive times [7]. For example, to switch off a machine tool if stand-by time is long enough [8]. PPC should use existing flexibility in machine schedule to stop, postpone or bring forward different process steps for implementing such stand-by strategies of machine tools. The Consultation Group of the European Commission estimates the saving potential of the optimization of waiting/start-up times at 10-25\% [5]. However, the task of an appropriate PPC-algorithm is to evaluate if shut-down and a start-up of a machine tool and its components is reasonable from the perspective of the whole production system and underlying process chain, since several important aspects have to be considered for the implementation of those strategies. For example, specific time and energy demand (e.g. maximum instantaneous peak power requirement, total energy consumption for start-up) is required both for start-up and poweroff stage [11]. Therefore, non-productive times have to be distributed appropriately in order to realize stand-by concepts [9]. Furthermore, intervals need to be long enough, e.g. in order to ensure thermal stability of machine tools by sufficient lead times [9]. PPC has to determine the holistic optimum: On the one hand it has to examine total energetic benefit including multiple machines, which might be affected by a redistribution of orders. On the other the PPC has to assess further organizational consequences, e.g. additional changeover time, operational readiness of the machine (since the gained energy saving should not sacrifice the process stability) product quality or machine tool availability [11] [9].

Third, Brecher et al. indicate that current control systems of machine tools should be extended, e.g. by systems for forecasting load detecting and visualization [9]. Based on information derived from the above mentioned measurement of energy consumption on component level, abilities of machine's path planning simulations can be enhanced, since the cumulative energy consumption can be calculated by the iterative summation of all individual cuts [7]. Those results should be linked with PPC so that the technical potential of machine tools can be used by providing them conditions for operating in their optimal range of efficiency.

To conclude, to equip PPC with advanced algorithms is a measure for achieving energy efficiency performance on a high scale. Benefits will be as follows: PPC works as leverage for EMS by putting findings from monitoring and simulation tasks into action. It also is in an enabler to use effectively the potential of energy optimized machine tools. PPC is a cost-effective instrument for using the given configuration of machine tool infrastructure in regard to energy efficiency as best as possible. Besides, it is a tool to detect the energy efficiency boundaries and to determine promising 
improvement potential at shop-floor level. Finally, it takes over the dynamic optimization in continuation of static improvement measures like investments in single components of machine tool or the new acquisition of whole machine tools with less energy consumption.

\section{$4 \quad$ Limitations and Practical Implications}

The elaborated concept is restricted to an outline for embedding energy efficiency in the planning and control logic of a conventional PPC. The conducted analysis focuses on creating the conceptual basis as well as the influencing factors and interconnected elements for further research. The conceptual integration of environmental-oriented optimization targets in existing PPC-algorithms will be conducted in a next step. The principles will be transferred to other processes than machining, e.g. milling and turning. The final concept has to be tested and validated within a manufacturing company. Due to the high significance of the energy consumption of machine tools, energy consumption is solely considered in this concept [5]. After validating energy-oriented PPC-logic variables should be supplemented by the consideration of other environmental factors, e.g. compressed air, coolant and lubricants.

The impact of the embedded energy efficiency PPC consists in achieving energy efficiency in interconnected processes and in particular beyond individual entities. This will result in a decrease of the environmental impact of the production site, saving of resources and reduction of costs: Total energy consumption will be reduced by exploiting load characteristics of machine tools as useful potential and embed them in the scheduling algorithms. Besides, production schedule can be aligned to advantageous time periods, e.g. when renewable energy is available or day-time dependent prices for electricity are low [10]. Furthermore, PPC can distribute machining tasks so that undesirable, high impact marginal energy peak loads can be avoided, which reduces energy costs and the environmental footprint of a production site [5]. A prospective, schematic application example for a scheduling approach considering peak power demands is given in Figure 2.

Furthermore, the adapted PPC will improve Life-Cycle-Assessments (LCA) by supporting the calculation and evaluation of the employed resources on individual product and process level. The PPC will deliver detailed information to enhance transparency and validity of product-specific environmental footprints.
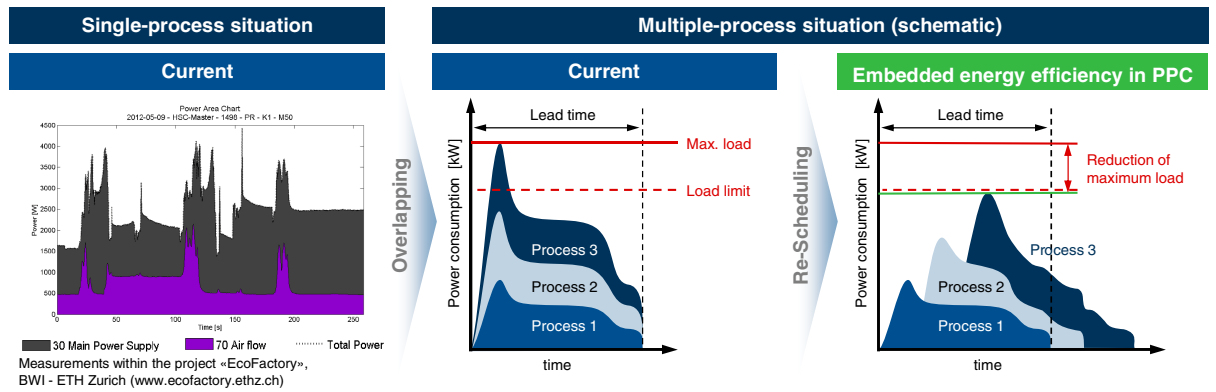

Fig. 2. Schematic example for scheduling considering peak power demands 


\section{Conclusion}

Existing conceptual elements from a top-down and bottom-up perspective are analyzed and systemized in regards to their contribution to embed energy efficiency in PPC. The integration of energy efficiency criteria in PPC will enable to achieve an economic and environmental performance optimum while fundamental technical and organizational requirements are assured at once. As automated, integrated solution it provides the ability of responsiveness of EMS by taking appropriate situationdepending, dynamic improvement measures. Hence, the value proposition of embedded energy efficiency in a PPC is the ability to link managerial targets with technical entities on the shop-floor by balancing and combining organizational prerequisites with technical capabilities.

\section{References}

1. Bunse, K., Vodicka, M., Schönsleben, P., Brülhart, M., Ernst, F.O.: Integrating energy efficiency performance in production management - gap analysis between industrial needs and scientific literature. Journal of Cleaner Production 19(6-7), 667-679 (2011)

2. International Energy Agency (IEA): Worldwide Trends in Energy Use and Efficiency, Key Insights from IEA Indicator Analysis (2008), http://www.iea.org/Textbase/ Papers/2008/indicators_2008.pdf (accessed May 14, 2012)

3. König, J.: Energieeffiziente Produktherstellung. In: Uhlmann, E. (ed.) FUTUR - Produktionstechnik für die Zukunft, vol. 12(2), pp. 12-13 (2010)

4. CECIMO: Concept Description for CECIMO's Self-Regulatory Initiative (SRI) for the Sector Specific Implementation of the Directive 2005/32/EC (2009),

http: / / www . eup-network. de/fileadmin/user_upload/Produktgruppen/ Lots/Working_Documents/Lot_ENTR_05_machine_tools/draft_self_reg ulation_machine_tools_2009-10.pdf (acessed May 14, 2012)

5. European Commission: ICT and Energy Efficiency in the Case for Manufacturing. Recommendations of the Consultation Group (2009), http: / / ec . europa . eu / information_society/events/ict4ee/2009/docs/files/ec/ec/ infso/g2/SmartManufacturing.pdf (accessed July 10, 2012)

6. Neugebauer, H., Westkämper, E., Klocke, F., Kuhn, A., Schenk, M., Michaelis, A., Spath, D., Weidner, E.: Abschlussbericht - Untersuchung zur Energieeffizienz in der Produktion. Fraunhofer-Gesellschaft zur FöRderung der Angewandten Forschung e.V., Chemnitz (2008)

7. Brecher, C., Boos, W., Klein, W., Kuhlmann, K., Triebs, J.: Ressourceneffizienzbewertung einer Werkzeugmaschine zur Steigerung ihrer Wirtschaftlichkeit. ZWF Zeitschrift für Wirtschaftlichen Fabrikbetrieb 104(9), 711-715 (2009)

8. Herrmann, C., Bergmann, L., Thiede, S., Zein, A.: Energy Labels for Production Machines - An Approach to Facilitate Energy Efficiency in Production Systems. In: Proceedings of 40th CIRP International Seminar on Manufacturing Systems Location (2007)

9. Brecher, C., Herfs, W., Heyers, C., Klein, W., Triebs, J., Beck, E., Dorn, T.: Ressourceneffizienz von Werkzeugmaschinen im Fokus der Forschung. Wt Werkstattstechnik Online 100(7/8), 559-564 (2010) 
10. Weinert, N., Chiotellis, S., Seliger, G.: Methodology for planning and operating energyefficient production systems. CIRP Annals - Manufacturing Technology 60(1), 41-44 (2011)

11. Li, W., Zein, A., Kara, S., Herrmann, C.: An Investigation into Fixed Energy Consumption of Machine Tools. In: Hesselbach, J., Herrmann, C. (eds.) Glocalized Solutions for Sustainability in Manufacturing: Proceedings of the 18th CIRP International Conference on Life Cycle Engineering, Braunschweig, pp. 268-273. Springer, Heidelberg (2011)

12. Karnouskos, S., Colombo, A.W., Martinez Lastra, J.L., Popescu, C.: Towards the energy efficient future Factory. In: Institute of Electrical and Electronics Engineers, 7th IEEE International Conference on Industrial Informatics (INDIN 2009), pp. 367-371. IEEE, Piscataway (2009)

13. Bunse, K., Sachs, J., Vodicka, M.: Evaluating Energy Efficiency Improvements in Manufacturing Processes. In: Vallespir, B., Alix, T. (eds.) APMS 2009. IFIP AICT, vol. 338, pp. 19-26. Springer, Heidelberg (2010)

14. Herrmann, C., Thiede, S., Kara, S., Hesselbach, J.: Energy oriented simulation of manufacturing systems - Concept and application. CIRP Annals - Manufacturing Technology 60, 45-48 (2011)

15. Vijayaraghavan, A., Dornfeld, D.: Automated energy monitoring of machine tools. CIRP Annals - Manufacturing Technology 59, 21-24 (2010)

16. Hermann, C., Thiede, S., Heinemann, T.: A Holistic Framework for Increasing Energy and Resource Efficiency in Manufacturing. In: Seliger, G., et al. (eds.) Advances in Sustainable Manufacturing: Proceedings of the 8th Global Conference on Sustainable Manufacturing, pp. 265-271. Springer, Heidelberg (2011)

17. Brecher, C., Bäumler, S., Bode, H., Breitbach, T., Hansch, S., Hennes, N., Prust, D., Tannert, M., Thoma, C., Wagner, P., Witt, S., Würz, T.: Ressourceneffizienz im Werkzeugmaschinenbau. In: Brecher, C., Klocke, F., Schmitt, R., Schuh, G. (eds.) Proceedings of Aachener Werkzeugmaschinenkolloquium (AWK) 2011 - Wettbewerbsfaktor Produktionstechnik: Aachener Perspektiven, Shaker Verlag, Aachen (2011)

18. Zein, A., Li, W., Herrmann, C., Kara, S.: Energy Efficiency Measures for the Design and Operation of Machine Tools: An Axiomatic Approach. In: Hesselbach, J., Herrmann, C. (eds.) Glocalized Solutions for Sustainability in Manufacturing: Proceedings of the 18th CIRP International Conference on Life Cycle Engineering, Braunschweig, Braunschweig, pp. 274-279. Springer, Heidelberg (2011) 